\title{
Novel in vitro and in vivo anti-Helicobacter pylori effects of pomegranate peel ethanol extract
}

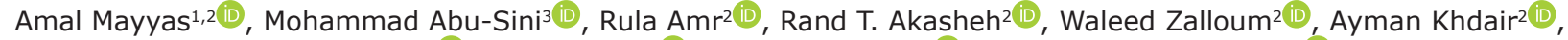 \\ Islam Hamad ${ }^{(\mathbb{D})}$, Talal Aburjai ${ }^{1}$ (D), Rula M. Darwish ${ }^{1}$ (i) and Luay Abu-Qatouseh ${ }^{4}$ (i)
}

1. Department of Pharmaceutical Sciences, Faculty of Pharmacy, University of Jordan, 11914 Amman, Jordan;

2. Department of Pharmacy, Faculty of Health Sciences, American University of Madaba, 11821 Madaba, Jordan;

3. Department of Pharmacy, Faculty of Pharmacy, Al-Zaytoonah University of Jordan, Amman, Jordan; 4. Department of Pharmacology and Biomedical Sciences, Faculty of Pharmacy, University of Petra, 961343 Amman, Jordan.

Corresponding author: Luay Abu-Qatouseh, e-mail: labuqatouseh@uop.edu.jo

Co-authors: AM: a.mayyas@aum.edu.jo, MA: mohammad.abusini@zuj.edu.jo,RA: r.amr@aum.edu.jo,

RTA: r.akasheh@aum.edu.jo,wZ: w.zalloum@aum.edu.jo, AK: khdair@fulbrightmail.org, IH: i.hamad@aum.edu.jo,

TA: aburjai@ju.edu.jo, RMD: rulad@ju.edu.jo

Received: 31-08-2020, Accepted: 01-12-2020, Published online: 16-01-2021

doi: www.doi.org/10.14202/vetworld.2021.120-128 How to cite this article: Mayyas A, Abu-Sini M, Amr R, Akasheh RT, Zalloum W, Khdair A, Hamad I, Aburjai T, Darwish RM, Abu-Qatouseh L (2021) Novel in vitro and in vivo anti-Helicobacter pylori effects of pomegranate peel ethanol extract, Veterinary World, 14(1): 120-128.

\begin{abstract}
Background and Aim: Interest in plants with antimicrobial properties has been revived due to emerging problems associated with using antibiotics to eradicate Helicobacter pylori. Accordingly, this study aims to assess the antibacterial effects of Punica granatum and the possible synergistic effect of its extract along with metronidazole against $H$. pylori.

Materials and Methods: Pomegranate peel ethanol extracts (PPEE) was tested against a control strain of H. pylori (NCTC 11916) in vitro and in vivo in female Wistar rats. Moreover, the synergistic effect of PPEE in combination with metronidazole was tested in vitro.

Results: The PPEE exhibited a remarkable activity against $H$. pylori with a minimum inhibitory concentration (MIC) of $0.156 \mathrm{mg} / \mathrm{mL}$. Furthermore, the extract exhibited a pronounced urease inhibitory activity $\left(\mathrm{IC}_{50} \sim 6 \mathrm{mg} / \mathrm{mL}\right)$ against the tested strain. A synergistic effect between PPEE and metronidazole was also observed (fractional inhibitory concentrations $<0.5$ ). Oral treatment of rats with PPEE for 8 days produced a significant reduction in $H$. pylori gastritis and a significant decrease in both lymphocytic and positive chronicity.
\end{abstract}

Conclusion: Pomegranate extract is probably safe and represents a potential alternative and complementary therapy for reducing $H$. pylori associated with gastric ulcers.

Keywords: Helicobacter pylori, in vitro, in vivo, pomegranate peel ethanol extracts, urease inhibition.

\section{Introduction}

Peptic ulcer disease caused by Helicobacter pylori infection is a worldwide problem [1]. H. pylori can weaken the protective mucus coating of the stomach and the upper part of the small intestine, making them more vulnerable to the acidic gastric juices. This could lead to gastritis and ulcers. Other complications include chronic gastritis, gastric carcinoma, and primary gastric B-cell lymphoma [2].

Ancient civilizations used medicinal plants to treat a wide range of diseases. And in modern medicine, these plants represent a rich source for drug discovery [3]. Plant extracts contain bioactive compounds that can be used prophylactically and therapeutically over synthetic drugs [4,5] and may display potent antimicrobial properties [6]. Punica granatum or

Copyright: Mayyas, et al. Open Access. This article is distributed under the terms of the Creative Commons Attribution 4.0 International License (http://creativecommons.org/licenses/ by/4.0/), which permits unrestricted use, distribution, and reproduction in any medium, provided you give appropriate credit to the original author(s) and the source, provide a link to the Creative Commons license, and indicate if changes were made. The Creative Commons Public Domain Dedication waiver (http:// creativecommons.org/publicdomain/zero/1.0/) applies to the data made available in this article, unless otherwise stated.
Pomegranate is one plant with great therapeutic potential. Pomegranate peel extract with its high antioxidant capacity exhibits anti-inflammatory and anti-ulcerogenic activities that are ten-fold higher than those of the pulp extract [7]. Moreover, research on the synergetic activity of pomegranate peel extract is sparse.

Accordingly, and as part of the Jordan traditional medicine project, the present study was designed to evaluate the anti- $H$. pylori and urease inhibitory activities of pomegranate peel ethanol extracts (PPEE) extract, and to investigate possible synergism between PPEE and metronidazole against this bacteria.

\section{Materials and Methods}

\section{Ethical approval}

This study was approved by the animal care committee at the University of Jordan.

\section{Study period and location}

This research was conducted for 8 months (between October 2015 and July 2016) at University of Jordan, Jordan.

\section{Chemicals and laboratory consumables}

Chemicals and solvents used in all experiments were of analytical grade. Solvents, including 
ethanol (EOH) and Dimethyl sulfoxide (DMSO), were purchased from LABCHEM (USA) and Fisher chemical (UK), respectively. Sterile blank disks of 6-mm diameter and disks with standard antibiotics (clarithromycin $15 \mu \mathrm{g}$, metronidazole $5 \mu \mathrm{g}$, ciprofloxacin $5 \mu \mathrm{g}$, and tetracycline $30 \mu \mathrm{g}$ ) were purchased from Oxoid (UK).

\section{Plant extraction}

Peels of P. granatum (Pomegranate) were collected from North Jordan and identified by direct comparison with the authenticated sample at the herbarium of the Faculty of Science and the Faculty of Agriculture at The University of Jordan. A voucher specimen was deposited with a voucher number of Pun-001.

Peels were air-dried under ambient conditions for 7 days, then powdered using an electric grinder and stored in plastic bags. Approximately $500 \mathrm{~g}$ of finely-powdered peels were soaked in $70 \% \mathrm{EtOH}$ in a closed container at room temperature at a ratio of 1:10 for 3 days. The pooled solvent was evaporated and produced a thick viscous pellet, which was further oven-dried at $50^{\circ} \mathrm{C}$ overnight, making a $27.77 \mathrm{~g} \%$ yield w/w.

\section{H. pylori isolation, culture media, and growth conditions}

Twelve H. pylori clinical isolates and one reference strain of $H$. pylori (NCTC 11916) were used in this study. The clinical strains were isolated from gastric biopsy samples obtained by a gastroenterologist at the Jordan University Hospital during a routine endoscopy. Gastric biopsies were processed according to standard methodology [8]. Briefly, each biopsy was homogenized using a tissue homogenizer (IKA, Staufen, Germany). Aliquots of $100 \mu \mathrm{L}$ of the homogenate were primarily cultured on Columbia blood agar (Oxoid, Hampshire, UK) supplemented with 7\% (v/v) horse blood and Dent selective supplement (Oxoid, Hampshire, UK). The same bacterial plates were used for subcultures but without the Dent supplement. All plates were incubated at $37^{\circ} \mathrm{C}$ under microaerophilic conditions using the CampyGen atmosphere generating system (Oxoid, Hampshire, UK) in anaerobic jars for 5-7 days. The growth of $H$. pylori was confirmed according to biochemical tests (positive for oxidase, catalase, and urease). H. pylori cultures were stored at $-70^{\circ} \mathrm{C}$ in trypticase soy broth (Oxoid, Hampshire, UK) containing $10 \%(\mathrm{v} / \mathrm{v})$ fetal calf serum (PAA, Pasching, Austria) and 15\% glycerol $[1,8]$. All experiments were performed in triplicates to ensure consistency of the results.

\section{Determination of $\boldsymbol{H}$. pylori inhibition zones}

The disk diffusion method was used to study the susceptibility of $H$. pylori to PPEE. The H. pylori suspension was prepared and adjusted to $6 \times 10^{8} \mathrm{CFU} / \mathrm{mL}$ ( $2 \mathrm{McF}$ arland) in a fixed volume of $100 \mu \mathrm{L}$ as described by Tayseer et al. [1] and Abu-Sini et al. [8]. The bacterial suspension was cultured on solid Columbia blood agar media. The PPEE stock solution was prepared by dissolving $2.5 \mathrm{~g}$ of the dry extract in a 2:1 (v/v) DMSOphosphate-buffered solution (PBS) (pH 6.8) to obtain $2.5 \mathrm{w} / \mathrm{v} \%$. Thereafter, $30 \mu \mathrm{L}$ of this extract were used to impregnate each of the sterile blank disks. These disks were left to dry, then placed on the H. pylori culture plates and incubated at $37^{\circ} \mathrm{C}$ for $1 \mathrm{~h}$ [9]. Disks with standard antibiotics (clarithromycin $15 \mu \mathrm{g}$, metronidazole $5 \mu \mathrm{g}$, ciprofloxacin $5 \mu \mathrm{g}$, and tetracycline $30 \mu \mathrm{g}$ ) were used as positive controls whereas, disks impregnated in a 2:1 (v/v) DMSO-PBS (pH 6.8) only were used as negative controls [1]. Finally, zones of inhibition were measured and recorded.

\section{Determination of minimum inhibitory concentration (MIC) of PPEE}

The two-fold agar dilution method was used to determine the MIC of PPEE against H. pylori. This was conducted according to the guidelines established by the Clinical and Laboratory Standards Institute [10]. The PPEE stock solutions were diluted in PBS (pH 6.8) by the following order: 1:2, 1:4, 1:8, $1: 16,1: 32,1: 64,1: 128,1: 256,1: 5121: 1024,1: 2048$, $1: 4096$, and 1:8192. Then, $1 \mathrm{~mL}$ of each diluted fraction was incorporated into $19 \mathrm{~mL}$ molten Columbia blood agar plates to final concentrations of 0.00061 $1.25 \mathrm{mg} / \mathrm{mL}$. Three $\mu \mathrm{L}$ of $H$. pylori $\left(6 \times 10^{8} \mathrm{CFU}\right)$ were applied on the surface of each plate and allowed to be dried before incubation.

\section{In vitro synergism effect between PPEE and metroni- dazole against $\boldsymbol{H}$. pylori}

Checkerboard test was used to investigate the synergism between PPEE and metronidazole $[1,8]$. PPEE $(0.1 \mathrm{~g} / \mathrm{mL})$ was dissolved in 2:1 (v/v) DMSOPBS (pH 6.8) then serially diluted to obtain $25,12.5$, $6.25,3.125,1.563,0.7813,0.3906,0.1953$, and $0.0977 \mathrm{mg} / \mathrm{mL}$. Furthermore, $51.2 \mathrm{mg}$ of metronidazole was dissolved in $10 \mathrm{~mL}$ of $1: 1(\mathrm{v} / \mathrm{v})$ DMSOdistilled water followed by serial dilutions in PBS $(\mathrm{pH}$ 6.8) to obtain $5.12,2.56,1.28,0.64,0.32,0.16,0.08$, and $0.04 \mathrm{mg} / \mathrm{mL}$. Thereafter, 1000 or $500 \mu \mathrm{L}$ from each diluted preparation was taken and mixed with $9.5 \mathrm{~mL}$ soft Columbia blood agar media. Then, fractional inhibitory concentrations (FICs) were calculated using the equation bellow. The FIC indices were interpreted as synergy if $<0.5$; additive if .0.5-1.0; indifference if 1.0-4.0; and antagonism if $>4.0$ [8].

$\mathrm{FIC}=(\mathrm{MIC}$ of drug $\mathrm{A}$ in combination/MIC of drug $\mathrm{A}$ alone $)+(\mathrm{MIC}$ of drug $\mathrm{B}$ in combination/MIC of drug $\mathrm{B}$ alone).

\section{Quantitative determination of urease inhibition concentration $\left(\mathrm{IC}_{50}\right)$}

Urease inhibition assay was performed as described by Nagata et al. [11], where urease inhibition served as a proxy for $H$. pylori inhibition. A $10 \mu \mathrm{L}$ of $6 \times 10^{8} \mathrm{CFU} / \mathrm{mL} H$. pylori suspension was challenged with $200 \mu \mathrm{L}$ of a detection reagent composed of $50 \mathrm{mM}$ PBS (pH 6.8) containing $500 \mathrm{mM}$ urea and $0.02 \%$ phenol red. Color development was monitored 
by measuring the O.D. at $555 \mathrm{~nm}$ wavelength in a 5-min interval. Samples of bacteria with a detection reagent only or PPEE with a detection reagent only served as controls. The following equation calculates the percentage of inhibition:

$\%$ inhibition $=([$ activity without plant extract - activity with plant extract]/[activity without plant extract] $) \times 100$.

A lack of potential urease inhibition was indicated if $\mathrm{IC}_{50}$ was more than $12.5 \mathrm{mg} / \mathrm{mL}$ (inhibition of $<60 \%$ ). The $\mathrm{IC}_{50}$ of PPEE was determined using $\mathrm{ED}_{50}$ plus (v1.0) software (Vergas, 2000). The urease inhibitory activity of PPEE was compared to the reference urease inhibitor acetohydroxamic acid (AHA) from Sigma (USA).

\section{Induction of $\boldsymbol{H}$. pylori infection in vivo}

Female Wistar rats were selected according to Crabtree et al. [12] selection criteria. Wistar rats were housed in the animal house of the University of Jordan, fed a commercial diet (Hammodeh factory, Jordan) $a d$ libitum and given sterile tap water. A total of 458 -weekold female Wistar-rats $(197.7 \pm 1.38 \mathrm{~g})$ were pre-treated with streptomycin suspended in tap water $(5 \mathrm{mg} / \mathrm{mL})$ for 3 days before the first $H$. pylori inoculation. After 1 day of fasting, rats were inoculated by gavage $1 \mathrm{~mL} / \mathrm{rat}$ with $H$. pylori suspension of 9 McFarland $\left(2.7 \times 10^{9}\right.$ $\mathrm{CFU} / \mathrm{mL}$ ) twice daily at an interval of $4 \mathrm{~h}$ [13], and for 8 consecutive days. Control rats were inoculated with sterile PBS (non-infected group). Eight weeks after the last inoculation, rats were sacrificed, and their stomachs were removed and sliced into three parts. The antrum region was used for the urease test, the second part for bacterial colonization and inflammatory response by culture, and rapid urease test. Another part of the stomach was rinsed in PBS and homogenized using a tissue homogenizer (Germany). Thereafter, aliquots of $100 \mu \mathrm{L}$ of the homogenate were cultured, as described above, following similar growth conditions. The remaining stomach part was fixed in $10 \%$ formalin. Samples were sent out to Alpha Medical for hematoxylin and eosin (H\&E) staining and histopathological analysis. Updated Sydney System with visual scales was used as a reference standard grading system. The density of H. pylori indicated if the case is acute infection, chronic inflammation, intestinal metaplasia, or atrophy $[3,14]$.

Infection with $H$. pylori was indicated if the rat met two or three of the following criteria: (a) A positive urease test of gastric biopsy; (b) a positive H. pylori growth in the cultured gastric biopsy; and/or (c) the presence of $H$. pylori curved bacilli in the gastric tissue by standard histological examination [13].

\section{Acute toxicity test of pomegranate extract}

Acute toxicity was evaluated in vivo in female Wistar rats. Tests were performed initially to ascertain the safety of the prepared doses of PPEE. According to the guidelines of the Organization for Economic and Cooperation and Development for testing of chemicals [15], three different doses of 50, 300, and
$2000 \mathrm{mg} / \mathrm{kg}$ were administered orally through gastric gavage to three different groups of rats $(\mathrm{n}=3$ per group) for the determination of the lethal dose that kills $50 \%$ of the test animals in a group $\left(\mathrm{LD}_{50}\right)$.

Rats were weighed before, during, and after the procedure to measure any changes in body weights. Rats were also monitored to observe any possible changes in their behaviors after dosing at least once during the first $30 \mathrm{~min}$ and periodically through $24 \mathrm{~h}$. Special attention was given during the early $4 \mathrm{~h}$ and daily for 14 days. Rats were monitored to observe any signs of toxicity including changes in skin and eyes, breathing issue, seizures, or death.

\section{Testing the effect of PPEE on $\boldsymbol{H}$. pylori}

Treatment with PPEE was initiated after 7 weeks of the last $H$. pylori inoculation. The treatment was prepared by dissolving $1250 \mathrm{mg}$ of PPEE in $100 \mathrm{~mL}$ water. A PPEE dose $50 \mathrm{mg} / \mathrm{kg}$ was administered twice daily for 8 days. The treatment was chosen based on a published protocol by Moghaddam et al. [7]. The PPEE dose represents $1 / 40$ of the highest safe dose tested in the acute toxicity study $(2000 \mathrm{mg} / \mathrm{kg})$.

Rats were randomly assigned into the following groups: (1) Non-infected treated $(n=9)$; (2) infected non-treated $(\mathrm{n}=13)$; (3) infected treated $(\mathrm{n}=13)$; and (4) non-infected non-treated $(n=10)$. Imbalance in the number of rats per group is attributed to their housing distribution into cages.

\section{Statistical analysis}

Chi-square test was used to test the difference between rat groups. $p<0.05$ was set to indicate statistical significance. Microsoft Windows 7 Excel program was used to conduct the analysis.

\section{Results}

\section{Pomegranate peel extract exhibits anti-H. pylori} activity in vitro

The antibacterial activity of PPEE against the control $H$. pylori strain of as represented by the inhibition zone was $32.53 \pm 0.33 \mathrm{~mm}$, compared to $65 \mathrm{~mm}$, $56 \mathrm{~mm}$, and $14 \mathrm{~mm}$ of ciprofloxacin, tetracycline, and clarithromycin, respectively, while no $H$. pylori inhibition by metronidazole was observed (Table-1).

The average MIC values of PPEE against the clinical $H$. pylori strains were $0.163 \pm 0.04 \mathrm{mg} / \mathrm{mL}$. In comparison, The MICs of ciprofloxacin and metronidazole (positive controls) were $0.00043 \pm 6.0 \times 10^{-5}$ and $0.442 \pm 0.035 \mathrm{mg} / \mathrm{mL}$, respectively (Table-2). Furthermore, the MIC of PPEE against the control H. pylori strain was $0.156 \mathrm{mg} / \mathrm{mL}$ as compared to $0.0006 \mathrm{mg} / \mathrm{mL}$ for ciprofloxacin, while the strain was resistant to metronidazole with a MIC of $0.256 \mathrm{mg} / \mathrm{mL}$. The $\mathrm{IC}_{50}$ for urease inhibition by PPEE was $6.3 \mathrm{mg} / \mathrm{mL}$.

\section{Pomegranate peel extract and metronidazole exhibit synergistic activity against $\boldsymbol{H}$. pylori}

According to the standard checkerboard test, the MIC for PPEE was $0.156 \mathrm{mg} / \mathrm{mL}$, and the MIC for PPEE in combination with metronidazole was 
Table-1: Inhibition zones $(\mathrm{mm})$ of PPEE $(0.75 \mathrm{mg} / \mathrm{disc})$ against clinical strains of $H$. pylori $(1-12)$ and the control strain.

\begin{tabular}{|c|c|c|c|c|c|c|c|c|c|c|c|c|c|}
\hline \multirow{2}{*}{$\begin{array}{l}\text { Experiment } \\
\text { number }\end{array}$} & \multicolumn{12}{|c|}{ Zones of inhibition $(\mathrm{mm})$ of clinical isolates } & \multirow{2}{*}{$\begin{array}{l}\text { Control Strain } \\
\text { (NCTC 11916) }\end{array}$} \\
\hline & 1 & 2 & 3 & 4 & 5 & 6 & 7 & 8 & 9 & 10 & 11 & 12 & \\
\hline Trial 1 & 20 & 19.8 & 32.3 & 29.2 & 28.2 & 24.8 & 29.2 & 30.2 & 23.4 & 29.5 & 28.6 & 31.1 & 33 \\
\hline Trial 2 & 18.8 & 19.3 & 30.5 & 30.6 & 28.3 & 26.1 & 27.8 & 28.2 & 22.8 & 29.2 & 27.8 & 30.2 & 32.7 \\
\hline Trial 3 & 19.1 & 22 & 31 & 32.1 & 30.1 & 25.4 & 29 & 32 & 22.7 & 30 & 30.1 & 31 & 31.9 \\
\hline Average & 19.3 & 20.37 & 31.27 & 30.63 & 28.87 & 25.43 & 28.67 & 30.13 & 22.97 & 29.57 & 28.83 & 30.77 & 32.53 \\
\hline \pm SEM & \pm 0.36 & \pm 0.83 & \pm 0.54 & \pm 0.84 & \pm 0.62 & \pm 0.38 & \pm 0.44 & \pm 1.09 & \pm 0.22 & \pm 0.23 & \pm 0.67 & \pm 0.28 & \pm 0.33 \\
\hline CIP & 20 & 60 & 0 & 50 & 53 & 65 & 59 & 0 & 0 & 64 & 50 & 55 & 65 \\
\hline MTZ & 0 & 0 & 0 & 0 & 0 & 0 & 0 & 0 & 0 & 0 & 0 & 0 & 0 \\
\hline DMSO-PBS & 0 & 0 & 0 & 0 & 0 & 0 & 0 & 0 & 0 & 0 & 0 & 0 & 0 \\
\hline
\end{tabular}

PPEE $=$ Pomegranate peel ethanol extracts, CIP=Ciprofloxacin, $M T Z=$ Metronidazole, $D M S O=$ Dimethyl sulfoxide, $\mathrm{PBS}=$ Phosphate buffer solution

$0.039 \mathrm{mg} / \mathrm{mL}$. The MIC for metronidazole was $0.256 \mathrm{mg} / \mathrm{mL}$, and the MIC for metronidazole in combination with PPEE was $0.016 \mathrm{mg} / \mathrm{mL}$. The FIC values and FIC index showed a synergic effect for the combination $(<0.5)$, where metronidazole FIC value mean (0.0625), PPEE FIC value mean (0.25), and FIC index (0.313). This indicates that the combination of PPEE with metronidazole was synergic.

Besides, PPEE was fractionated by column chromatography using solvents differing in their polarity; hexane, chloroform, ethyl acetate, butanol, and water. Fractions were assessed for their potential anti-H. pylori activity using antimicrobial susceptibility tests and in vitro interaction between the isolated compounds and Metronidazole (Synergism). A total of $0.3 \mathrm{mg} /$ disk of butanol fraction displayed the highest inhibition zone of $15.6 \pm 0.3 \mathrm{~mm}$ among other fractions. Moreover, we performed a phytochemical analysis of the butanol fraction, which revealed the presence of gallic acid, mannitol sugar, and 5-hydroxy methyl furfural. Gallic acid, the major component in this fraction showed weak anti-H. pylori activity. On the other hand, gallic acid did not show any synergistic activity with metronidazole. Furthermore, 5-hydroxy methyl furfural was not tested against $H$. pylori as it was present in very minute amount in the butanol extract.

\section{Acute in vivo administration of pomegranate peel} extract shows no signs of toxicity

During the 14 days of the experiment, even with a high PPEE dose of $2000 \mathrm{mg} / \mathrm{kg}$, no significant change in rats' weight compared with the control group was noticed ( $p>0.05)$. Moreover, no signs of toxicity or deaths were reported. The $\mathrm{LD}_{50}$ value was indeterminable even at the highest PPEE dose, which indicates that PPEE is non-toxic at doses of expected efficacy. Results show that the extract is non-toxic even at relatively high concentrations (Table-3). Based on these findings, the starting PPEE dose was selected at $1 / 40^{\text {th }}$ of $2000 \mathrm{mg} / \mathrm{kg}$ or $50 \mathrm{mg} / \mathrm{kg}$.

\section{Pomegranate peel extract inhibits $\boldsymbol{H}$. pylori infection and pathology in vivo \\ Infected non-treated group}

Gastric culture from all infected rats showed well-identified $H$. pylori colonies, positive Gram stain microscopic test, and positive catalase, and oxidase and urease activity tests. Specimens showed contamination with Candida, and other bacteria and spores and dysplasia were noticed in some infected stomachs (Figure-1). Bacterial urease activity was detected for each antral stomach part by developing an intense pink color for the urease reagent within $24 \mathrm{~h}$ (Figure-2). Histopathological analysis revealed H. pylori positivity in $100 \%$ of stomach specimens. Active infection was also found in $46.1 \%$ of the samples and positive chronicity in $84.6 \%$ (Figures-3-5, Table-4).

\section{Infected treated group}

Urease positivity was observed in $23 \%$ of the gastric samples. Moreover, $61.5 \%$ of histopathological specimens showed $H$. pylori positive gastric mucosa. Chronicity and infection activity were observed in $23 \%$ and $15.3 \%$ of rat specimens, respectively (Table-4).

Chi-square test indicated a significant difference $(p<0.05)$ between infected treated and non-infected treated rats in terms of urease activity (Figure-2), treatment effects on eradicating H. pylori (Figure-3), the chronicity of gastric infection, and the percentage of infection activity (Figures-4 and 5). This indicates that PPEE treatment displayed potent anti- $H$. pylori activity.

\section{Non-infected treated group}

Gastric culture showed no characteristic H. pylori Colonies in all samples. We observed Candida and other bacterial contamination. Moreover, $88.9 \%$ of gastric samples were urease negative, and histopathology results showed gastric mucosa with no $H$. pylori in $100 \%$ specimens. Chronicity and infection activity were found in $33.3 \%$ and $11.1 \%$ of the samples, respectively (Table-4).

\section{Non-infected non-treated group}

The gastric culture showed no characteristic H. pylori colonies in all samples. We observed contamination of Candida and other bacteria. While $80 \%$ of gastric samples were urease negative, all histopathological sections of gastric mucosa were $H$. pylori negative. Chronicity was detected in $30 \%$ of these 





Table-3: Signs of acute in vivo toxicity in response to PPEE.

\begin{tabular}{lccccc}
\hline Group & $\mathbf{n}$ & PPEE dose $(\mathbf{m g} / \mathbf{k g})$ & $\begin{array}{c}\text { Average weight before } \\
\text { treatment } \pm \text { SEM }(\mathbf{g})\end{array}$ & $\begin{array}{c}\text { Average weight after } \\
\text { treatment } \pm \text { SEM }(\mathbf{g})\end{array}$ & Number of dead rats \\
\hline 1 & 3 & 2000 & $260 \pm 16.3$ & $262.5 \pm 21.6$ & 0 \\
2 & 3 & 300 & $263.75 \pm 20.6$ & $280 \pm 11.5$ & 0 \\
3 & 3 & 50 & $250 \pm 26.3$ & $253.75 \pm 11.1$ & 0 \\
\hline
\end{tabular}

PPEE $=$ Pomegranate peel ethanol extracts
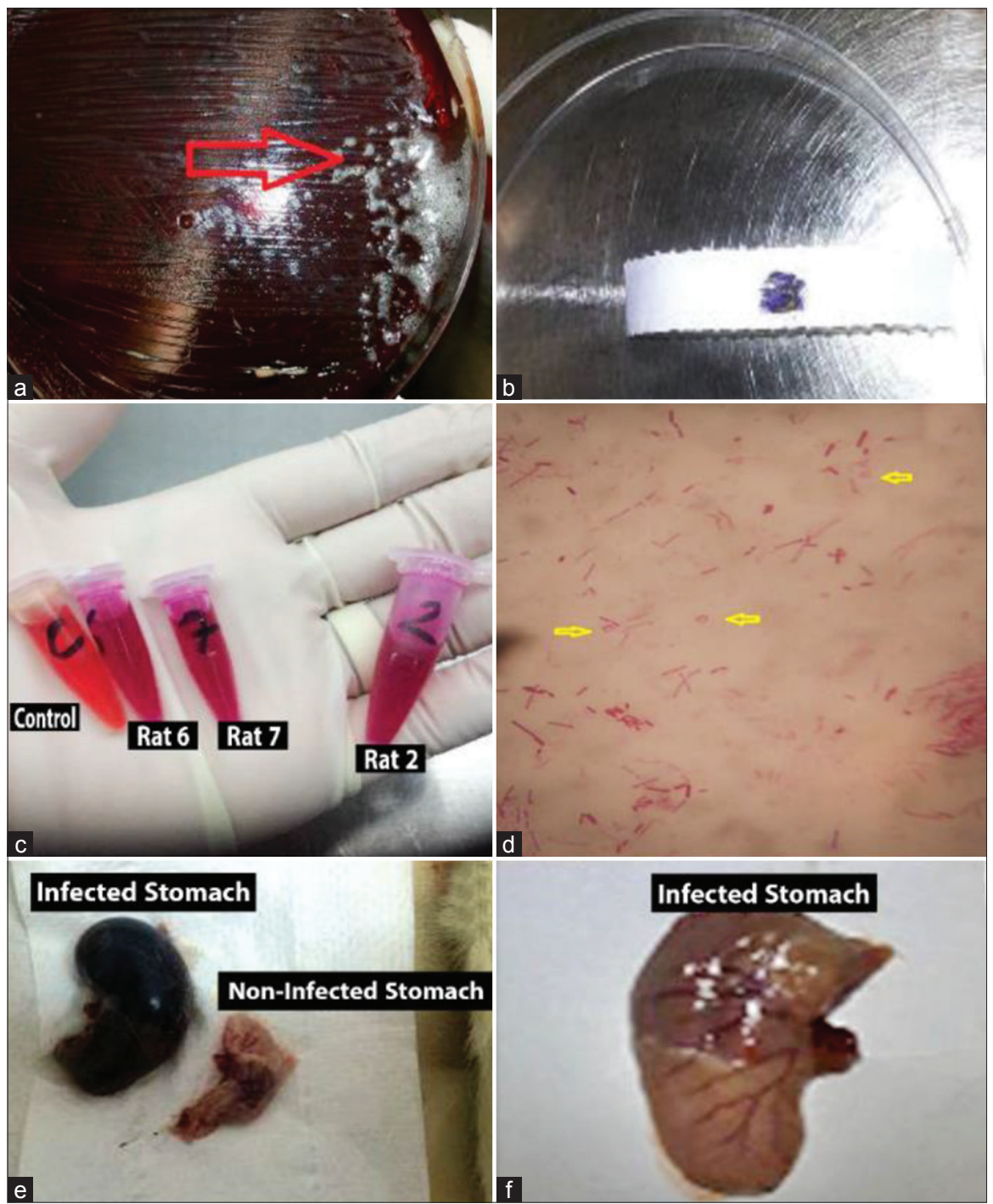

Figure-1: Indications of Helicobacter pylori infection in rat stomach. $H$. pylori positivity in cultures of gastric biopsies of rats as indicated by (a) catalase; (b) oxidase; (c) and urease activities; and (d) Gram (-ve) staining of selected colonies, where H. pylori looks spiral, as curved rods, coccoidal or U-shaped. (e) and (f) Stomachs from infected versus non-infected rats.

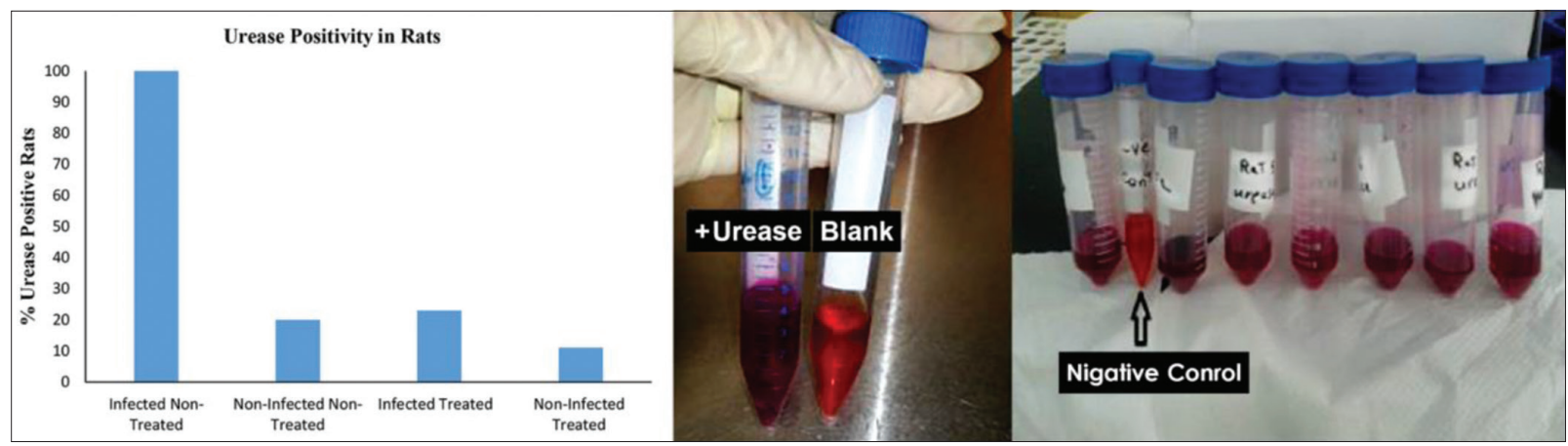

Figure-2: Efficacy of pomegranate peel extract in inhibiting urease activity in vivo. Left: Percentage of rats with urease activity in the antral stomachs in four experimental groups. Data are expressed as mean \pm SEM. $p<0.05$ between infected non-treated and infected treated groups. Right: Positive urease activity detected in the antral stomach of infected non-treated rats. 
Table-4: Histopathological and urease tests of rat stomachs after 8 weeks of the last $H$. pylori inoculation.

\begin{tabular}{|c|c|c|c|c|c|}
\hline Rat groups & Number of Helic & acter pylo & ve rats/n & & Number of urease \\
\hline Infected non-treated & $\begin{array}{l}13 / 13 \\
\text { Infection activity } \\
6 / 13\end{array}$ & $\begin{array}{l}\text { chronicity } \\
11 / 13\end{array}$ & $\begin{array}{l}\text { Lymphocyte } \\
5 / 13\end{array}$ & $\begin{array}{l}\text { neutrophils } \\
11 / 13\end{array}$ & $13 / 13(100 \%)$ \\
\hline Infected treated & $\begin{array}{l}8 / 13 \\
\text { Infection activity } \\
2 / 13\end{array}$ & $\begin{array}{l}\text { Chronicity } \\
3 / 13\end{array}$ & $\begin{array}{l}\text { Lymphocyte } \\
10 / 13\end{array}$ & $\begin{array}{l}\text { neutrophils } \\
12 / 13\end{array}$ & $3 / 13(23 \%)$ \\
\hline Non-infected non-treated & $\begin{array}{l}0 / 10 \\
\text { Infection activity } \\
0 / 10\end{array}$ & $\begin{array}{l}\text { chronicity } \\
3 / 10\end{array}$ & $\begin{array}{l}\text { Lymphocyte } \\
5 / 10\end{array}$ & $\begin{array}{l}\text { neutrophils } \\
7 / 10\end{array}$ & $2 / 10(20 \%)$ \\
\hline Non-infected treated & $\begin{array}{l}0 / 9 \\
\text { Infection activity } \\
1 / 9 \\
\text { Infection activity } \\
9 / 45\end{array}$ & $\begin{array}{l}\text { Chronicity } \\
3 / 9 \\
\text { chronicity } \\
20 / 45\end{array}$ & $\begin{array}{l}\text { Lymphocyte } \\
7 / 9 \\
\text { Lymphocyte } \\
27 / 45\end{array}$ & $\begin{array}{l}\text { Neutrophils } \\
9 / 9 \\
\text { Neutrophils } \\
39 / 45\end{array}$ & $1 / 9(11.1 \%)$ \\
\hline
\end{tabular}

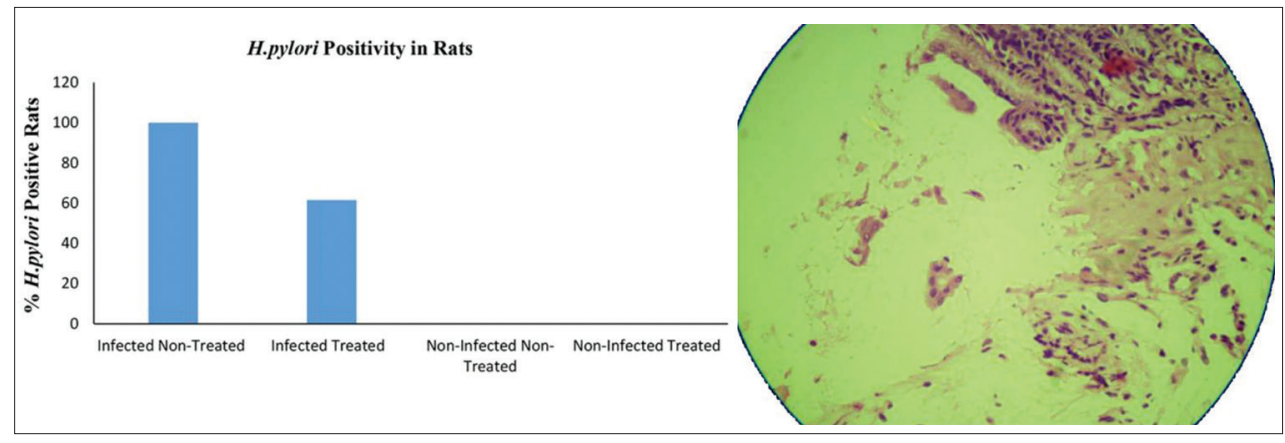

Figure-3: Efficacy of pomegranate peel extract in eradicating Helicobacter pylori in vivo. Left: Percentage of $\mathrm{H}$. pyloripositive rats in four experimental groups. Data are expressed as mean $\pm S E M . p<0.05$ between infected non-treated and infected treated groups. Right: H\&E-stained section of rat stomach showing $H$. pylori Gram (-ve) curved rods.

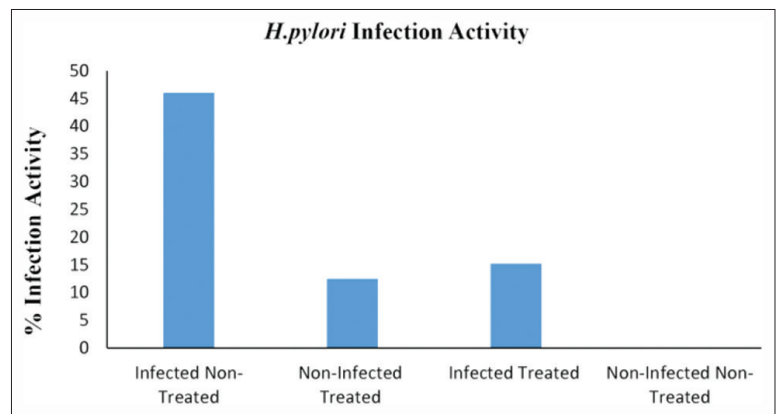

Figure-4: The effect of pomegranate peel extract on Helicobacter pylori infection chronicity in vivo. Left: Percentage of rats with $H$. pylori Chronicity in H\&E-stained stomach sections in four experimental groups. Data are expressed as mean \pm SEM. $p<0.05$ between infected non-treated and infected treated groups. Right: Chronic gastritis in a section of H\&E-stained stomach from an $H$. pylori-infected rat, with typical mixed lymphoid reaction in the gastric mucosa.

infection and to study $H$. pylori-associated gastrointestinal pathology.

Based on the in vitro $H$. pylori and urease inhibition activities of PPEE, we used this extract to treat H. pylori-infected Wistar rats. To the best of our knowledge, this is the first report to show that PPEE can treat $H$. pylori infection in vivo. Other studies reported the potential usefulness of Pomegranate fruit juice or rind (REF). Moghaddam et al. [7] reported that the hydroalcoholic extract of Pomegranate fruit peel exhibits potential antiulcer properties in Wistar rats. Such efficacy was attributed to the high antioxidant activity of Pomegranate fruit extract [7]. Future studies may focus on exploring the bioactive ingredients in pomegranate peel that may be responsible for its anti-H. pylori effects. Matsubara et al. [20] found that the antioxidative flavonoid epigallocatechin gallate (the main component in green tea extracts) exhibits potent $H$. pylori urease inhibitory activity with an $\mathrm{IC}_{50}$ value of lower than that of acetohydroxamic acid in vitro. Notably, the most abundant catechins in Pomegranate are the potent antioxidant epicatechin and epigallocatechin gallate [21]. This hints that the anti-H. pylori effects of pomegranate peel may at least in part be attributed to its catechins.

In our study, PPEE treatment led to a modest reduction in $H$. pylori colonization and infection in Wistar rats $(\sim 39 \%$ treatment rate, $\mathrm{p}<0.05)$ after 8 days of treatment with a PPEE dose of $50 \mathrm{mg} / \mathrm{kg}$. The treatment also significantly reduced infection chronicity $(p<0.05)$. Furthermore, the anti-inflammatory effect of PPEE on gastric mucosa was remarkable. Since PPEE demonstrated no signs of acute toxicity at much higher doses $(2000 \mathrm{mg} / \mathrm{kg})$, it would be interesting to test the potency of higher PPEE doses ( $>50 \mathrm{mg} / \mathrm{kg}$ ) against H. pylori. This study is superior to other studies that used Pomegranate extracts for anti-ulcerogenic and anti-inflammatory activities in non- $H$. pylori models $[6,7]$. 


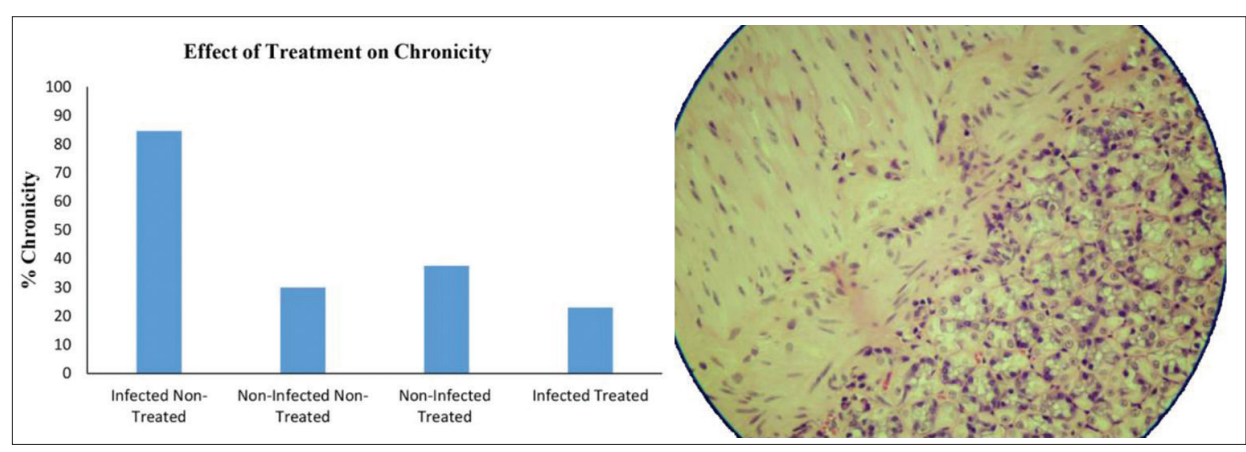

Figure-5: The effect of pomegranate peel extract on Helicobacter pylori infection activity in vivo. Percentage of rats with active infections as evaluated on H\&E-stained sections of stomachs from four experimental groups. Data are expressed as mean \pm SEM. $\mathrm{p}<0.05$ between infected non-treated and infected treated groups.

\section{Conclusion}

Pomegranate peel extract exhibited remarkable activity against $H$. pylori in vitro with a MIC of $0.156 \mathrm{mg} / \mathrm{mL}$, and a pronounced urease inhibitory activity with an $\mathrm{IC}_{50}$ of $\sim 6 \mathrm{mg} / \mathrm{mL}$ against the tested strain. We found a synergic effect of PPEEmetronidazole combination against $H$. pylori with an FIC of $<0.5$. Oral treatment of rats with PPEE for 8 days led to a significant reduction in $H$. pylori gastritis, in addition to a significant decrease in both lymphocytic and positive chronicity. Importantly, PPEE showed no signs of acute in vivo toxicity even at relatively high doses. Therefore, we propose PPEE as a potential alternative or complementary therapy to treat H. pylori infection associated with clinical symptoms, but more investigations are needed.

\section{Authors' Contributions}

AM and MAS performed the experiments. AM wrote the paper. LA, RMD, and AK conceived and designed the microbiological and biological activities. TA and WZ designed the extracted solutions and their corresponding experiments. RA, RTA, and IH analyzed and interpreted the data. All authors have read and approved the final manuscript.

\section{Acknowledgments}

The authors of this work would sincerely acknowledge the support of Deanship of Higher Education of the University of Jordan for partially funding this project on 25-04-2020. We also would extend our thanks to the Jordan Company of antibody Production (Monojo) for valuable technical support.

\section{Competing Interests} interests.

The authors declare that they have no competing

\section{Publisher's Note}

Veterinary World remains neutral with regard to jurisdictional claims in published institutional affiliation.

\section{References}

1. Tayseer, I., Aburjai, T., Abu-Qatouseh, L., AL-Karabieh, N., Ahmed, W. and Al-Samydai, A. (2020) In vitro
anti-Helicobacter pylori activity of capsaicin. J. Pure Appl. Microbiol., 14(1): 279-286.

2. Waldum, H.L., Kleveland, P.M. and Sørdal, Ø.F. (2016) Helicobacter pylori and gastric acid: An intimate and reciprocal relationship. Ther. Adv. Gastroenterol., 9(6): 836-844.

3. Price, A.B. (1991) The Sydney system: Histological division. J. Gastroenterol. Hepatol., 6(3): 209-222.

4. Modolo, L.V., de Souza, A.X., Horta, L.P., Araujo, D.P. and de Fatima, A. (2015) An overview on the potential of natural products as ureases inhibitors: A review. J. Adv. Res., 6(1): 35-44.

5. Malm, A., Glowniak-Lipa, A., Korona-Glowniak, I. and Baj, T. (2015) Anti-Helicobacter pylori activity in vitro of chamomile flowers, coneflower herbs, peppermint leaves and thyme herbs-a preliminary report. Curr. Issues Pharm. Med. Sci., 28(1): 30-32.

6. Zanetti, M., Carniel, T.K., Dalcanton, F., dos Anjos, R.S., Riella, H.G., de Araujo, P.H. and Fiori, M.A. (2018) Use of encapsulated natural compounds as antimicrobial additives in food packaging: A brief review. Trends Food Sci. Tech., 81(1): 51-60.

7. Moghaddam, G., Sharifzadeh, M., Hassanzadeh, G., Khanavi, M. and Hajimahmoodi, M. (2013) Antiulcerogenic activity of the pomegranate peel (Punica granatum) methanol extract. Food Nutr. Sci., 4(10): 43.

8. Abu-Sini, M., Mayyas, A., Al-Karablieh, N., Darwish, R., Al-Hiari, Y., Aburjai, T. and Abu-Qatouseh, L. (2017) Synthesis of 1, 2, 3-triazolo [4, 5-h] quinolone derivatives with novel antimicrobial properties against metronidazole resistant Helicobacter pylori. Molecules, 22(5): 841.

9. Nuraddin, S.M., Amin, Z.A., Sofi, S.H. and Osman, S. (2019) Antibacterial and anti-ulcerogenic effects of Punica granatum peel extract against ethanol-induced acute gastric lesion in rats. Zanco J. Med. Sci., 23(3): 308-314.

10. Wayne,P.A. (2011) Performance Standards for Antimicrobial Susceptibility Testing. Clinical and Laboratory Standards Institute, United Kingdom.

11. Nagata, K., Mizuta, T., Tonokatu, Y., Fukuda, Y., Okamura, H., Hayashi, T. and Tamura, T. (1992) Monoclonal antibodies against the native urease of Helicobacter pylori: Synergistic inhibition of urease activity by monoclonal antibody combinations. Infect. Immun., 60(11): 4826-4831.

12. Crabtree, J.E., Court, M., Aboshkiwa, M.A., Jeremy, A.H., Dixon, M.F. and Robinson, P.A. (2004) Gastric mucosal cytokine and epithelial cell responses to Helicobacter pylori infection in Mongolian gerbils. J. Pathol., 202(2): 197-207.

13. Werawatganon, D. (2014) Simple animal model of Helicobacter pylori infection. World J. Gastroenterol., 20(21): 6420.

14. Suzana, M.K., Skender, T., Emine, D.S., Halil, A., Vjollca, S.M., Agron, K. and Arijeta, P. (2009) Helicobacter pylori gastritis updated Sydney classification applied in our material. Sec. Biol. Med. Sci., 30(1): 45-60.

15. OECD. (1981) Guidelines for the Testing of Chemicals, 
Test Guideline. OECD, Paris, France. p201.

16. Hajimahmoodi, M., Shams-Ardakani, M., Saniee, P., Siavoshi, F., Mehrabani, M., Hosseinzadeh, H. and Shafiee, A. (2011) In vitro antibacterial activity of some Iranian medicinal plant extracts against Helicobacter pylori. Nat. Prod. Res., 25(11): 1059-1066.

17. Voravuthikunchai, S.P., Limsuwan, S. and Mitchell, H. (2006) Effects of Punica granatum pericarps and Quercus infectoria nutgalls on cell surface hydrophobicity and cell survival of Helicobacter pylori. J. Health Sci., 52(2): 154-159.

18. Rizvanov, A., Haertlé, T., Bogomolnaya, L. and Talebi Bezmin Abadi, A. (2019) Helicobacter pylori and its antibiotic heteroresistance: A neglected issue in published guidelines. Front. Microbiol., 10(1): 1796.

19. Li, H., Kalies, I., Mellgård, B. and Helander, H.F. (1998) A rat model of chronic Helicobacter pylori infection: Studies of epithelial cell turnover and gastric ulcer healing. Scand. J. Gastroenterol., 33(4): 370-378.

20. Matsubara, S., Shibata, H., Ishikawa, F., Yokokura, T., Takahashi, M., Sugimura, T. and Wakabayashi, K. (2003) Suppression of Helicobacter pylori-induced gastritis by green tea extract in Mongolian gerbils. Biochem. Biophys. Res. Commun., 310(3): 715-719.

21. Mortazaeinezhad, F., Safavi, K., Esfahani, A.A. and Shirvani, M.E. (2014) Comparing different cultivars of Iranian pomegranate by the amount of epicatechin and epigallocatechin gallate. Annu. Res. Rev., 4(8): 1339-1345.

$* * * * * * * *$ 